\title{
Synthesis and Characterization of Side-Chain Liquid Crystalline Polydienes and Their Hydrogenated Derivatives
}

\author{
Yusuke KawaKami, ${ }^{*}$ Motokuni IChitani, ${ }^{*}$ Hideo Kunisada, ${ }^{*}$ and Yasuo Yuki*, \\ Graduate School of Materials Science, Japan Advanced Institute of Science and Technology, \\ Asahidai 1-1, Tatsunokuchi, Ishikawa 923-12, Japan \\ * Department of Materials Science and Engineering, Nagoya Institute of Technology. \\ Gokiso, Showa-ku, Nagoya 466, Japan
}

(Received October 30, 1995)

\begin{abstract}
Polydienes having mesogenic groups in the side chain and their hydrogenated derivatives were synthesized by the radical polymerization of diene derivatives with siloxane linkage in the spacer and benzoates as mesogenic groups, followed by hydrogenation of the double bond of the main chain. The stereochemistry of the main chain is principally $(E)-1,4)$ elucidated by NOESY spectrum. The diene polymers take smectic liquid crystalline state, basically with fan like structure, irrespective of spacer length. The hydrogenated polymers did not take clear mesophase structures.
\end{abstract}

KEY WORDS Diene/Siloxane / Radical Polymerization / Structural Isomer / Hydrogenation / Thermal Analysis / Liquid Crystalline Polymers / Smectic /

The temperature range and the mesophase structure of side-chain liquid crystalline polymers are very much dependent on the chemical structure of the polymer, namely, main chain, spacer, and mesogenic groups. After the original research by Finkelmann, ${ }^{1,2}$ extensive research has been carried out on side-chain liquid crystalline polymers to combine the properties of polymers and electrooptic property of the low molecular mass mesogen. ${ }^{3}$ Poly(acrylate)s and poly(methacrylate)s, derived by polymerization of polar vinyl monomers, are commonly used as hydrocarbon main-chain components. There are rather few examples in which other main chain structures like polyolefin and poly(vinyl ether) are used. ${ }^{4-13}$

The glass transition and clearing temperatures of the typical side-chain liquid crystalline polymers are shown in Table I. It can be clearly seen that the transition temperature, the mesomorphic temperature range, and the mesophase structures of the side-chain liquid crystalline polymers very much depend on the chemical structure of the main chain.

At the same time, it is generally considered that the spacer groups, which act as flexible connecting groups between main chain and mesogenic groups, are also important in determining the mesophase structure by making it easy for the mesogenic groups to be organized into a liquid crystalline state. This situation can be said to fit the case of polymethacrylate main chain, whose $T_{\mathrm{g}}$ is as high as $100^{\circ} \mathrm{C}$, with more flexible oligomethylenes as spacer groups. The oligomethylene groups really act as flexible connecting groups between main chain and mesogenic groups.

Although polysiloxane is widely used as a flexible main chain component of side-chain liquid crystalline polymers, ${ }^{4-6}$ the situation should be said a little different in the cases of polysiloxane main chain polymers. Namely, the main chain itself is very flexible, even more flexible than the usually used oligomethylene spacer. Nevertheless, the siloxane linkage could be used as a com-

\footnotetext{
† To whom correspondence should be addressed.
}

ponent of the spacer by taking advantage of its flexibility. However, there are only few examples where siloxane linkage is used as a spacer component. There, the siloxane linkage is introduced into the middle of the oligomethylene spacer group of a vinyl polymer in order to avoid the steric hindrance of dimethyl-substituted siloxane linkage which would interfere with the aggregation of mesogenic groups if introduced close to the main chain. ${ }^{14,15}$ We reported a new type of side-chain liquid crystalline polydiene in which the main chain is connected to mesogenic cyanobiphenyl derivatives through the spacer having disiloxane linkages directly attached to the main chain in every four carbons to avoid steric hindrance. ${ }^{16,17)}$

In this report we report a new series of liquid crystalline polydienes with disiloxane or trisiloxane linkage in the spacer group and phenyl benzoate derivatives as mesogenic groups.

\section{EXPERIMENTAL}

\section{General}

${ }^{1} \mathrm{H}$ NMR spectra were obtained on a Varian $200 \mathrm{MHz}$ spectrometer Model Gemini 200. Chemical shifts are

Table I. Glass transition and clearing temperatures of typical side-chain liquid crystalline polymers ${ }^{4}$

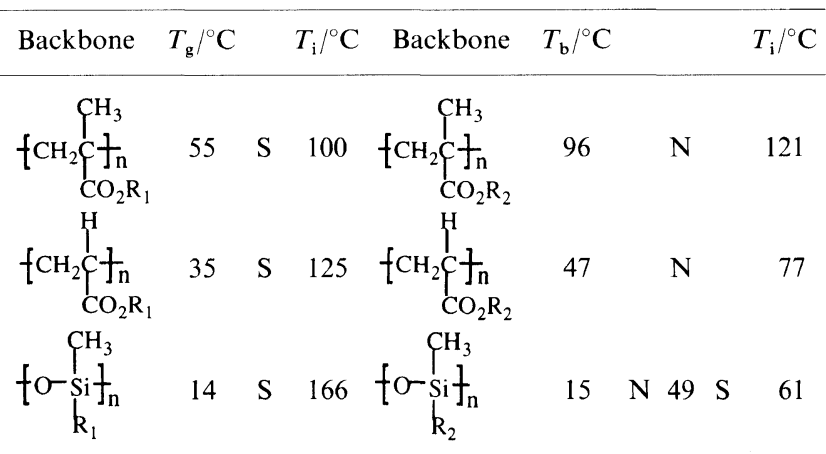

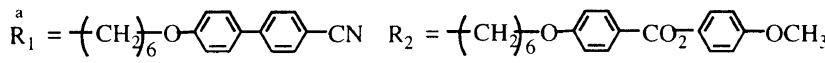

$\mathrm{S}$, smectic; $\mathrm{N}$, nematic. 
given in ppm from tetramethylsilane (TMS) in $\mathrm{CDCl}_{3}$. GPC analyses were carried out on a Tosoh (TSK) GPC Model HLC 802 equipped with TSK gels G3000H (exclusion molecular weight, polystyrene $6 \times 10^{4}$ ) and $\mathrm{G} 5000 \mathrm{H}$ (exclusion molecular weight, polystyrene $4 \times$ $10^{6}$ ), using chloroform or tetrahydrofuran as an eluent at the flow rate of $1 \mathrm{~mL} \mathrm{~min}^{-1}$.

DSC analyses of monomers and polymers were carried out on a SEIKO thermal analysis system Model SSC 5500 equipped with DSC 100 with the heating rate of $5 \mathrm{Cmin}^{-1}$. The transition temperature is given at the point where transition starts. The temperature was calibrated by the use of indium and tin metals as standards $\left(156.6^{\circ} \mathrm{C}\right.$ for indium and $231.9^{\circ} \mathrm{C}$ for tin).

Optical polarization micrographs were taken on a Nikon optical polarization micrograph Model OPTIPHOTO-POL equipped with a Mettler thermal analysis system Model FP800 with FP82 hot stage and FP 80 controller. Pictures were taken at a little lower temperature than the peak after annealing in cooling from isotropic state at appropriate intervals.

\section{Synthesis}

The sythetic method of the monomers is quite similar to those reported for butadiene monomer containing cyanobiphenyl as the mesogenic group. ${ }^{16,17}$ Structures and abbreviated names are given.

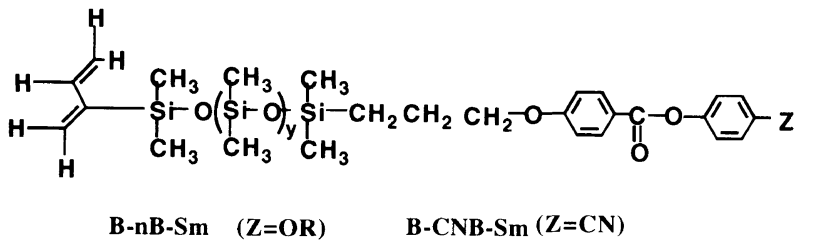

$n=$ number of carbon atoms in the alkoxy tail $(n=1,3-6)$ $m=2 y+6(y=0$ or 1$)$

Structure and abbreviated names of the monomers

The abbreviated names of the monomers are given by a combination of $\mathrm{B}$, which indicates butadiene, $\mathrm{ab}$ breviated names of the mesogen; $\mathrm{CN}(\mathrm{Z}=\mathrm{CN}), 1 \mathrm{~B}(\mathrm{Z}=$ $\left.\mathrm{OCH}_{3}\right), 3 \mathrm{~B}\left(\mathrm{Z}=\mathrm{OC}_{3} \mathrm{H}_{7}\right), 4 \mathrm{~B}\left(\mathrm{Z}=\mathrm{OC}_{4} \mathrm{H}_{9}\right), 5 \mathrm{~B}\left(\mathrm{Z}=\mathrm{OC}_{5}{ }^{-}\right.$ $\left.\mathrm{H}_{11}\right)$, and $6 \mathrm{~B}\left(\mathrm{Z}=\mathrm{OC}_{6} \mathrm{H}_{13}\right)$, and the abbreviated name of the spacer; $\mathrm{S} 6\left[\mathrm{Si}\left(\mathrm{CH}_{3}\right)_{2} \mathrm{OSi}\left(\mathrm{CH}_{3}\right)_{2} \mathrm{CH}_{2} \mathrm{CH}_{2} \mathrm{CH}_{2} \mathrm{O}\right]$ and $\mathrm{S} 8\left[\mathrm{Si}\left(\mathrm{CH}_{3}\right)_{2} \mathrm{OSi}\left(\mathrm{CH}_{3}\right)_{2} \mathrm{OSi}\left(\mathrm{CH}_{3}\right)_{2} \mathrm{CH}_{2} \mathrm{CH}_{2} \mathrm{CH}_{2} \mathrm{O}\right]$.

Examples are B-CNB-S6 and B-1B-S8 in which the 4$\{(4-c y a n o p h e n y l o x y c a r b o n y l) p h e n y l$ mesogenic group is attached to the diene function through the spacer containing a disiloxane linkage $(m=6)$, and 4-\{(4-methoxyphenyloxycarbonyl)phenyl through spacer containing trisiloxane linkage $(m=8)$, respectively.

Protons of diene, spacer and biphenyl parts are designated as below in assigning the ${ }^{1} \mathrm{H}$ NMR spectra. Protons of the tail group $\left(\mathrm{Z}=\mathrm{OCH}_{3}, \mathrm{OC}_{4} \mathrm{H}_{9}, \mathrm{OC}_{6} \mathrm{H}_{13}\right)$ are designated separately.

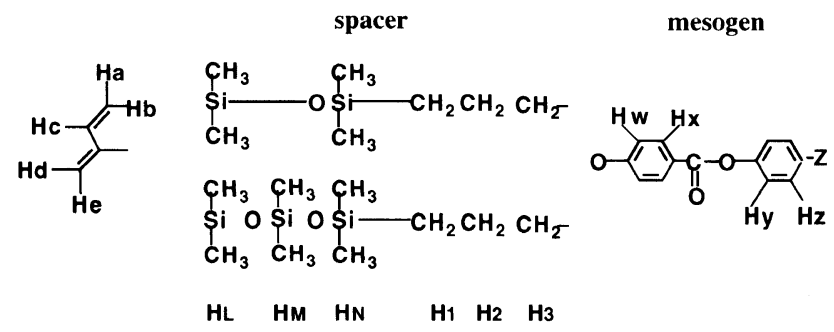

4-Allyloxybenzoyl chloride (bp $115-120^{\circ} \mathrm{C}$ at $8 \mathrm{mmHg}$ ) was synthesized by the chlorination of 4-allyloxybenzoic acid $\left(\mathrm{mp} 168^{\circ} \mathrm{C}\right)$ obtained by the allylation of 4-hydroxybenzoic acid with allyl bromide in the presence of excess potassium hydroxide and catalytic amounts of potassium iodide. 4-Alkoxyphenols $(n=3-6)$ were obtained by the alkylation of hydroquinone with alkyl bromide in the presence of excess sodium hydroxide. The products were recrystallized from the mixed solvent of acetone and hexane. All products gave reasonable elemental and spectroscopic analyses data. The melting points of the products were $52^{\circ} \mathrm{C}, 61^{\circ} \mathrm{C}, 44^{\circ} \mathrm{C}$, and $45^{\circ} \mathrm{C}$ for 4-propoxy-, 4-butoxy-, 4-pentyloxy-, and 4-hexyloxyphenol, respectively.

4-Alkyloxyphenyl 4-allyloxybenzoates were synthesized by the esterification of 4-allyloxybenzoyl chloride with 4-alkyloxyphenols in the presence of triethylamine. The products were purified by recrystallization from acetone and hexane mixed solvents. All the products gave reasonable elemental and spectroscopic analyses data. The compounds were abbreviated as $\mathrm{A}-n \mathrm{~B}(\mathrm{Z}=\mathrm{OR}$; $n$, number of carbon atoms in the tail) or $\mathrm{A}-\mathrm{CNB}(\mathrm{Z}=$ $\mathrm{CN})$. The melting points of the products were $89.2^{\circ} \mathrm{C}$, $71.8^{\circ} \mathrm{C}, 71.0^{\circ} \mathrm{C}, 65.8^{\circ} \mathrm{C}$, and $61.8^{\circ} \mathrm{C}$ for 4 -methoxy-(A1B), 4-propoxy-(A-3B), 4-butoxy-(A-4B), 4-pentyloxy(A-5B), and 4-hexyloxyphenyl(A-6B) 4-allyloxybenzoate (A-CNB), respectively.

The 4-alkyloxyphenyl 4-allyloxybenzoates were converted to 4-alkyloxyphenyl 4-(3-dimethylchlorosilyl)propoxybenzoate by hydrosilylation reaction with dimethylchlorosilane in the presence of chloroplatinic acid in toluene(methoxy, propoxy, and butoxy) or tetrahydrofuran (pentyloxy or hexyloxy). The reaction proceeded quantitatively. 4-Canophenyl 4-(3-dimethylchlorosilyl)propoxybenzoate was similarly synthesized. The products were used for the following reactions without isolation or purification.

2-(Chlorodimethylsilyl)-1,3-butadiene and 2-(3-chlorotetramethyldisiloxanyl)-1,3-butadiene were obtained by reaction of dimethyldichlorosilane or 1,3-dichlorotetaramethyldisiloxane with 1,3-butadienyl-2-magnesium chloride, the Grignard reagent from chloroprene. ${ }^{18)} 2$ (Hydoxydimethylsilyl)-1,3-butadiene and 2-(3-hydroxytetramethyldisiloxanyl)-1,3-butadiene were synthesized by the hydrolysis of corresponding chlorosilyl derivatives under buffered neutral condition.

The monomers were synthesized by condensation reaction of 4-alkyloxyphenyl 4'-(3-dimethylchlorosilyl)propoxybenzoate and 2-(hydroxydimethylsilyl)-1,3-butadiene or 2-(3-hydroxytetramethyldisiloxanyl)-1,3-butadiene in the presence of pyridine.

\section{2-(Hydoxydimethylsilyl)-1,3-butadiene}

Chemical shifts: 0.30 (s with fine coupling, $6 \mathrm{H}, H_{\mathrm{L}}$ ), 2.44 (broad s, $1 \mathrm{H}, \mathrm{OH}), 5.12$ (d with fine coupling, $1 \mathrm{H}$, $\left.J_{1}=10.0 \mathrm{~Hz}, H_{\mathrm{a}}\right), 5.39$ (d with fine coupling, $1 \mathrm{H}, J_{1}=$ $17.6 \mathrm{~Hz}, H_{\mathrm{b}}$ ), 5.55 (d with fine coupling, $1 \mathrm{H}, J_{1}=2.5 \mathrm{~Hz}$ $H_{\mathrm{d}}$ ), 5.78 (d with fine coupling, $1 \mathrm{H}, J_{1}=2.5 \mathrm{~Hz}, H_{\mathrm{e}}$ ), 6.46 (dd with fine coupling, $1 \mathrm{H}, J_{1}=10.0 \mathrm{~Hz}, J_{3}=17.6 \mathrm{~Hz}$, $H_{\mathrm{c}}$ ).

\section{2-(3-Hydroxytetramethyldisiloxanyl)-1,3-butadiene} Chemical shifts: 0.12 (s with fine coupling, $6 \mathrm{H}, H_{\mathrm{M}}$ ), 
0.28 (s with fine coupling, $\left.6 \mathrm{H}, H_{\mathrm{L}}\right), 2.46$ (broad s, $1 \mathrm{H}$, $\mathrm{O} H), 5.11$ (d with fine coupling, $1 \mathrm{H}, J_{1}=10.0 \mathrm{~Hz}, H_{\mathrm{a}}$ ), 5.36 (d with fine coupling, $\left.1 \mathrm{H}, J_{1}=17.6 \mathrm{~Hz}, H_{\mathrm{b}}\right), 5.53(\mathrm{~d}$ with fine coupling, $1 \mathrm{H}, J_{1}=2.5 \mathrm{~Hz}, H_{\mathrm{d}}$ ), 5.76 (d with fine coupling, $1 \mathrm{H}, J_{1}=2.5 \mathrm{~Hz}, H_{\mathrm{e}}$ ), 6.47 (dd with fine coupling, $1 \mathrm{H}, J_{1}=10.0 \mathrm{~Hz}, J_{3}=17.6 \mathrm{~Hz}, H_{\mathrm{c}}$ ).

2-[3-\{3-[4-\{(4-Methoxyphenyloxycarbonyl $)$ phenyl $\}$ oxy $]-$ propyl $\}$ tetramethyldisiloxanyl]-1,3-butadiene $[B-1 B-S 6]$

$R f=0.45$; eluent, hexane $:$ acetone $=97: 3$. Yield $24 \%$. $\mathrm{mp} 46^{\circ} \mathrm{C}$.

Chemical shifts: 0.12 (s with fine coupling, $6 \mathrm{H}, H_{\mathrm{N}}$ ), 0.26 (s with fine coupling, $\left.6 \mathrm{H}, H_{\mathrm{L}}\right), 0.68\left(\mathrm{~m}, 2 \mathrm{H}, H_{1}\right)$, $1.87\left(\mathrm{~m}, 2 \mathrm{H}, \mathrm{H}_{2}\right), 3.84\left(\mathrm{~s}, 3 \mathrm{H}, \mathrm{OCH}_{3}\right), 4.02(\mathrm{t}, 2 \mathrm{H}, \mathrm{J}=$ $\left.6.6 \mathrm{~Hz}, H_{3}\right), 5.11$ (d with fine coupling, $1 \mathrm{H}, J_{1}=10.0 \mathrm{~Hz}$, $H_{\mathrm{a}}$ ), 5.36 (d with fine coupling, $1 \mathrm{H}, J_{1}=17.6 \mathrm{~Hz}, H_{\mathrm{b}}$ ), 5.54 (d with fine coupling, $\left.1 \mathrm{H}, J_{1}=2.5 \mathrm{~Hz}, H_{\mathrm{d}}\right), 5.76(\mathrm{~d}$ with fine coupling, $1 \mathrm{H}, J_{1}=2.5 \mathrm{~Hz}, H_{\mathrm{e}}$ ), 6.47 (dd with fine coupling, $\left.1 \mathrm{H}, J_{1}=10.0 \mathrm{~Hz}, J_{3}=17.6 \mathrm{~Hz}, H_{\mathrm{c}}\right), 6.93$, 6.99 (two d, $4 \mathrm{H}, J=9.3 \mathrm{~Hz}, H_{\mathrm{z}}, H_{\mathrm{w}}$ ), 7.13 (d, $2 \mathrm{H}$, $\left.J=9.3 \mathrm{~Hz}, H_{\mathrm{y}}\right), 8.13\left(\mathrm{~d}, 2 \mathrm{H}, J=9.3 \mathrm{~Hz}, H_{\mathrm{x}}\right)$.

2-[3-\{3-[4-\{(4-Propoxyphenyloxycarbonyl )phenyl $\}$ oxy $]-$ propyl $\}$ tetramethyldisiloxanyl]-1,3-butadiene $[B-3 B-S 6]$

$R f=0.43$; eluent, hexane $:$ acetone $=9: 1$. Yield $16 \%$. $\mathrm{mp} 5^{\circ} \mathrm{C}$.

Chemical shifts: 0.13 (s with fine coupling, $6 \mathrm{H}, H_{\mathrm{N}}$ ), 0.25 (s with fine coupling, $\left.6 \mathrm{H}, H_{\mathrm{L}}\right), 0.68\left(\mathrm{~m}, 2 \mathrm{H}, H_{1}\right)$, $1.06\left(\mathrm{t}, 3 \mathrm{H}, J=7.0 \mathrm{~Hz}, \mathrm{OCH}_{2} \mathrm{CH}_{2} \mathrm{CH}_{3}\right), 1.83(\mathrm{~m}, 2 \mathrm{H}$, $\left.\mathrm{OCH}_{2} \mathrm{CH}_{2} \mathrm{CH}_{3}\right), 1.86\left(\mathrm{~m}, 2 \mathrm{H}, \mathrm{H}_{2}\right), 3.93(\mathrm{t}, 2 \mathrm{H}, J=$ $\left.7.0 \mathrm{~Hz}, \mathrm{OCH}_{2} \mathrm{CH}_{2} \mathrm{CH}_{3}\right), 4.00\left(\mathrm{t}, 2 \mathrm{H}, J=6.6 \mathrm{~Hz}, \mathrm{H}_{3}\right)$, 5.11 (d with fine coupling, $\left.1 \mathrm{H}, J_{1}=10.5 \mathrm{~Hz}, H_{\mathrm{a}}\right), 5.35(\mathrm{~d}$ with fine coupling, $1 \mathrm{H}, J_{1}=17.6 \mathrm{~Hz}, H_{\mathrm{b}}$ ), 5.52 (d with fine coupling, $1 \mathrm{H}, J_{1}=2.5 \mathrm{~Hz}, H_{\mathrm{d}}$ ), 5.76 (d with fine coupling, $1 \mathrm{H}, J_{1}=2.5 \mathrm{~Hz}, H_{\mathrm{e}}$ ), 6.46 (dd with fine coupling, $1 \mathrm{H}, J_{1} 10.5 \mathrm{~Hz}, J_{3}=17.6 \mathrm{~Hz}, H_{\mathrm{c}}$ ) $6.92,6.98$ (two $\left.\mathrm{d}, 4 \mathrm{H}, J=9 . \overline{3} \mathrm{~Hz}, H_{\mathrm{z}}, H_{\mathrm{w}}\right), 7.11\left(\mathrm{~d}, 2 \mathrm{H}, J=9.3 \mathrm{~Hz}, H_{\mathrm{y}}\right)$, $8.14\left(\mathrm{~d}, 2 \mathrm{H}, J=9.3 \mathrm{~Hz}, H_{\mathrm{x}}\right)$.

2-[3-\{3-[4-\{(4-Butoxyphenyloxycarbonyl $)$ phenyl $\}$ oxy $]-$ propyl $\}$ tetramethyldisiloxanyl $]-1,3$-butadiene $[B-4 B-S 6]$

$R f=0.45$; eluent, hexane $:$ dichloromethane $=7: 3$. This compound was further purified by column chromatography on ODS gel using methanol as the eluent. Yield $19 \%$. mp $20.2^{\circ} \mathrm{C}$.

Chemical shifts: $0.98\left(\mathrm{t}, 3 \mathrm{H}, J=7.0 \mathrm{~Hz}, \mathrm{OCH}_{2} \mathrm{CH}_{2}-\right.$ $\left.\mathrm{CH}_{2} \mathrm{CH}_{3}\right), 1.51\left(\mathrm{~m}, 2 \mathrm{H}, \mathrm{OCH}_{2} \mathrm{CH}_{2} \mathrm{CH}_{2} \mathrm{CH}_{3}\right), 1.79(\mathrm{~m}$, $\left.2 \mathrm{H}, \mathrm{OCH}_{2} \mathrm{CH}_{2} \mathrm{CH}_{2} \mathrm{CH}_{3}\right), 3.96\left(\mathrm{t}, 2 \mathrm{H}, \mathrm{J}=7.0 \mathrm{~Hz}, \mathrm{OCH}_{2}-\right.$ $\mathrm{CH}_{2} \mathrm{CH}_{2} \mathrm{CH}_{3}$ ).

2-[3-\{3-[4-\{(4-Pentyloxyphenyloxycarbonyl $)$ phenyl $\}-$ oxy $]$ propyl $\}$ tetramethyldisiloxanyl $]-1,3-$ butadiene $[B-$ 5B-S6]

$R f=0.41$; eluent, hexane : acetone $=9: 1$. Yield $10 \%$. $\mathrm{mp}-1^{\circ} \mathrm{C}$.

Chemical shifts: $0.94\left(\mathrm{t}, 3 \mathrm{H}, J=7.0 \mathrm{~Hz}, \mathrm{OCH}_{2} \mathrm{CH}_{2}\right.$ $\left.\mathrm{CH}_{2} \mathrm{CH}_{2} \mathrm{CH}_{3}\right), 1.44\left(\mathrm{~m}, 2 \mathrm{H}, \mathrm{OCH}_{2} \mathrm{CH}_{2} \mathrm{CH}_{2} \mathrm{CH}_{2} \mathrm{CH}_{3}\right)$, $1.68\left(\mathrm{~m}, 2 \mathrm{H}, \mathrm{OCH}_{2} \mathrm{CH}_{2} \mathrm{CH}_{2} \mathrm{CH}_{2} \mathrm{CH}_{3}\right), 1.81(\mathrm{~m}, 2 \mathrm{H}$, $\left.\mathrm{OCH}_{2} \mathrm{CH}_{2} \mathrm{CH}_{2} \mathrm{CH}_{2} \mathrm{CH}_{3}\right), 3.97\left(\mathrm{t}, 2 \mathrm{H}, J=7.0 \mathrm{~Hz}, \mathrm{OCH}_{2}-\right.$ $\mathrm{CH}_{2} \mathrm{CH}_{2} \mathrm{CH}_{2} \mathrm{CH}_{3}$ ).
2-[3-\{3-[4-\{(4-Hexyloxyphenyloxycarbonyl $)$ phenyl $\}-$ oxy $]$ propyl $\}$ tetramethyldisiloxanyl $]-1,3-$ butadiene $[B$ 6B-S6]

$R f=0.43$; eluent, hexane : acetone $=9: 1$. Yield $18 \%$. $\mathrm{mp} 5^{\circ} \mathrm{C}$.

Chemical shifts: $0.92\left(\mathrm{t}, 3 \mathrm{H}, J=7.0 \mathrm{~Hz}, \mathrm{OCH}_{2} \mathrm{CH}_{2}\right.$ $\left.\mathrm{CH}_{2} \mathrm{CH}_{2} \mathrm{CH}_{2} \mathrm{CH}_{3}\right), 1.26\left(\mathrm{~m}, 2 \mathrm{H}, \mathrm{OCH}_{2} \mathrm{CH}_{2} \mathrm{CH}_{2} \mathrm{CH}_{2}-\right.$ $\left.\mathrm{CH}_{2} \mathrm{CH}_{3}\right), 1.35\left(\mathrm{~m}, 2 \mathrm{H}, \mathrm{OCH}_{2} \mathrm{CH}_{2} \mathrm{CH}_{2} \mathrm{CH}_{2} \mathrm{CH}_{2} \mathrm{CH}_{3}\right)$, $1.52\left(\mathrm{~m}, 2 \mathrm{H}, \mathrm{OCH}_{2} \mathrm{CH}_{2} \mathrm{CH}_{2} \mathrm{CH}_{2} \mathrm{CH}_{2} \mathrm{CH}_{3}\right), 1.82(\mathrm{~m}, 2 \mathrm{H}$, $\left.\mathrm{OCH}_{2} \mathrm{CH}_{2} \mathrm{CH}_{2} \mathrm{CH}_{2} \mathrm{CH}_{2} \mathrm{CH}_{3}\right), 3.98(\mathrm{t}, 2 \mathrm{H}, J=7.0 \mathrm{~Hz}$, $\mathrm{OCH}_{2} \mathrm{CH}_{2} \mathrm{CH}_{2} \mathrm{CH}_{2} \mathrm{CH}_{2} \mathrm{CH}_{3}$ ).

Other signals of B-4B-S6, B-5B-S6, and B-6B-S6 were observed at reasonable and similar positions with $\mathrm{B}$ 3B-S6.

$2-[3-\{3-[4-\{(4-C y a n o p h e n y l o x y c a r b o n y l) p h e n y l\} o x y]-$ propyl $\}$ tetramethyldisiloxanyl $]-1,3$-butadiene $[B-C N B$ S6]

$R f=0.43$; eluent, hexane : acetone $=8: 2$. This compound was further purified by column chromatography on ODS gel using methanol-water $(95: 5)$ as the eluent. Yield $15 \%$. mp $34.4^{\circ} \mathrm{C}$.

Chemical shifts: 0.12 (s with fine coupling, $6 \mathrm{H}, H_{\mathrm{N}}$ ), 0.25 (s with fine coupling, $\left.6 \mathrm{H}, H_{\mathrm{L}}\right), 0.68\left(\mathrm{~m}, 2 \mathrm{H}, H_{1}\right)$, $1.85\left(\mathrm{~m}, 2 \mathrm{H}, H_{2}\right), 4.00\left(\mathrm{t}, 2 \mathrm{H}, J=6.6 \mathrm{~Hz}, H_{3}\right), 5.10(\mathrm{~d}$ with fine coupling, $1 \mathrm{H}, J_{1}=10.5 \mathrm{~Hz}, H_{\mathrm{a}}$ ), 5.35 (d with fine coupling, $1 \mathrm{H}, J_{1}=18.0 \mathrm{~Hz}, H_{\mathrm{b}}$ ), 5.50 (d with fine coupling, $1 \mathrm{H}, J_{1}=1.8 \mathrm{~Hz}, H_{\mathrm{d}}$ ), 5.73 (d with fine coupling, $1 \mathrm{H}, J_{1}=1.8 \mathrm{~Hz}, H_{\mathrm{e}}$ ) 6.45 (dd with fine coupling, $1 \mathrm{H}$, $\left.J_{1}=10.5 \mathrm{~Hz}, J_{3}=18.0 \mathrm{~Hz}, H_{\mathrm{c}}\right), 6.98(\mathrm{~d}, 2 \mathrm{H}, J=9.3 \mathrm{~Hz}$, $\left.H_{\mathrm{w}}\right), 7.35\left(\mathrm{~d}, 2 \mathrm{H}, J=9.3 \mathrm{~Hz}, H_{\mathrm{y}}\right), 7.72(\mathrm{~d}, 2 \mathrm{H}, J=9.3 \mathrm{~Hz}$, $\left.H_{\mathrm{z}}\right), 8.12\left(\mathrm{~d}, 2 \mathrm{H}, J=9.3 H_{\mathrm{x}}\right)$.

2-[5-\{3-[4-\{(4-Methoxyphenyloxycarbonyl $)$ phenyl $\}$ oxy $]-$ propyl $\}$ hexamethyltrisiloxanyl $]-1,3$-butadiene $[B-1 B-S 8]$

$R f=0.40$; eluent, hexane : acetone $=8: 2$. Yield $20 \%$. $\mathrm{mp} 44^{\circ} \mathrm{C}$.

2-[5-\{3-[4-\{(4-Butoxyphenyloxycarbonyl $)$ phenyl $\}$ oxy $]$ propyl $\}$ hexamethyltrisiloxanyl]-1,3-butadiene [B-4B-S8]

$R f=0.42$; eluent, hexane $:$ acetone $=9: 1$. Yield $17 \%$. $\mathrm{mp} 10^{\circ} \mathrm{C}$.

2-[5-\{3-[4-\{(4-Hexyloxyphenyloxycarbonyl $)$ phenyl $\}-$ oxy] propyl hexamethyltrisiloxanyl $]-1,3$-butadiene [B$6 B-S 8]$

$R f=0.43$; eluent, hexane $:$ acetone $=95: 5$. Yield $25 \%$. $\mathrm{mp}-6^{\circ} \mathrm{C}$.

$2-[5-\{3-[4-\{(4-C y a n o p h e n y l o x y c a r b o n y l)$ phenyl $\}$ oxy $]-$ propyl $\}$ hexamethyltrisiloxanyl $]-1,3$-butadiene $[B-C N B$ S8]

$f=0.44$; eluent, hexane : acetone $=7: 3$. Yield $21 \%$. Transition temperatures $-58,-45,-15^{\circ} \mathrm{C}$.

Monomers with S8 as the spacer showed new singlet at $0.05 \mathrm{ppm}$ (s with fine coupling, $6 \mathrm{H}, H_{\mathrm{M}}$ ) in addition to the signals shown by corresponding monomers with S6 as the spacer. All the monomers synthesized gave reasonable elemental analysis data.

\section{Polymerization}

Benzene was dried over calcium hydride, or lithium aluminum hydride prior to use. Monomers were dried 
under vacuum at $60^{\circ} \mathrm{C}$ for 1 day after purification. Polymerizations were usually carried out in bulk using AIBN as an initiator at $60^{\circ} \mathrm{C}$ (reaction time $24 \mathrm{~h}$ ). Formed polymers were recovered by precipitation into methanol. In the GPC chromatograms of polymers before purification, a low molecular weight fraction was sometimes observed. Such an oligomer fraction was removed by repeated reprecipitation into methanol or hexane[poly(BCNB-S8] from dichloromethane or chloroform[poly(B$4 \mathrm{~B}-\mathrm{S} 8)]$ solution. The absence of monomer in the polymerization product was checked by thin layer chromatography and GPC.

The names of polymers are abbreviated by the use of the combination of $P$ and the abbreviated name of the monomer. For example, poly(B-1B-S6) is abbreviated as PB-1B-S6.

The ${ }^{1} \mathrm{H}$ NMR data of polymers are given.

\section{$P B-1 B-S 6$}

Chemical shifts: $0.12\left(\mathrm{~s}, 6 \mathrm{H}, H_{\mathrm{M}}\right), 0.15\left(\mathrm{~s}, 6 \mathrm{H}, H_{\mathrm{L}}\right)$, $0.63\left(\mathrm{~m}, 2 \mathrm{H}, H_{1}\right), 1.82\left(\mathrm{~m}, 2 \mathrm{H}, H_{2}\right), 2.19$ (broad s, 4H, $\left.H_{\mathrm{a}}, H_{\mathrm{b}}, H_{\mathrm{d}}, H_{\mathrm{e}}\right), 3.80\left(\mathrm{~s}, 3 \mathrm{H}, \mathrm{OCH}_{3}\right), 3.94\left(\mathrm{~m}, 2 \mathrm{H}, H_{3}\right)$, $5.86\left(\mathrm{~s}, 1 \mathrm{H}, H_{\mathrm{c}}\right), 6.90\left(\mathrm{~d}, 4 \mathrm{H}, J=9.3 \mathrm{~Hz}, H_{\mathrm{z}}, H_{\mathrm{w}}\right), 7.09$ $\left(\mathrm{d}, 2 \mathrm{H}, J=9.3 \mathrm{~Hz}, H_{\mathrm{y}}\right), 8.09\left(\mathrm{~d}, 2 \mathrm{H}, J=9.3 \mathrm{~Hz}, H_{\mathrm{x}}\right)$.

Other polymers with $\mathrm{S} 6$ as the spacer gave the signals of main chain, spacer, and mesogen at similar positions with PB-1B-S6 and those of a tail group at similar positions with corresponding monomers. Polymers with $\mathrm{S} 8$ as the spacer gave new singlet at $0.05 \mathrm{ppm}(\mathrm{s}, 6 \mathrm{H}$, $H_{\mathrm{M}}$ ) in addition to the signals shown by corresponding polymers with S6 as the spacer.

\section{Hydrogenation of Polymers}

Polymers were dissolved in toluene $(7 \mathrm{~mL})$, and reduced with 5 times excess $p$-toluenesulfonylhydrazide in the presence of small amounts of $t$-butylcatechol at $110^{\circ} \mathrm{C}$ for 48 hours. The recovery yield is around $75 \%$ after precipitaion in methanol. The names of hydrogenated polymers are abbreviated by the use of the combination of $\mathrm{PH}$ and the abbreviated name of the monomer. For example, hydrogenated polymer of poly(B-1B-S6) is abbreviated as PHB-1B-S6.

The ${ }^{1} \mathrm{H}$ NMR data of the polymer are given.

\section{PHB-1B-S6}

Chemical shifts: $0.09\left(\mathrm{~s}, 12 \mathrm{H}, H_{\mathrm{L}}, H_{\mathrm{M}}\right), 1.2-1.8$ (broad $\left.\mathrm{m}, 7 \mathrm{H}, H_{\text {main chain }}\right)$.

\section{PHB- $1 B-S 8$}

Chemical shifts: $0.09\left(\mathrm{~s}, 18 \mathrm{H}, H_{\mathrm{L}}, H_{M}, H_{\mathrm{N}}\right), 1.2-1.8$ (broad $\mathrm{m}, 7 \mathrm{H}, H_{\text {main chain }}$ ).

The olefinic proton at around $5.86 \mathrm{ppm}$ completely disappeared. Other signals appeared at reasonable and similar positions compared to the original diene polymers.

\section{RESULTS AND DISCUSSION}

\section{Synthesis and Polymerization}

In monomer synthesis by forming siloxane linkage, caution must be taken to purify the product very carefully to avoid contamination by bis(diene-functionalized) product. All monomers gave rather poor to reasonable
Table II. Radical polymerization of monomers by AIBN

\begin{tabular}{lcccc}
\hline Monomer & Yield $/ \%$ & $M_{w}\left(\times 10^{4}\right)^{\mathrm{a}}$ & $M_{n}\left(\times 10^{4}\right)^{\mathrm{a}}$ & $M_{w} / M_{n}{ }^{\mathrm{a}}$ \\
\hline B-1B-S6 & 58 & 28.0 & 6.6 & 4.2 \\
B-3B-S6 & 43 & 31.3 & 11.5 & 2.7 \\
B-4B-S6 & 41 & 6.5 & 4.3 & 1.5 \\
B-5B-S6 & 48 & 30.8 & 8.3 & 3.7 \\
B-6B-S6 & 39 & 37.1 & 11.1 & 3.3 \\
B-CNB-S6 & 68 & 11.2 & 6.6 & 1.7 \\
B-1B-S8 & 43 & 33.3 & 8.8 & 3.8 \\
B-4B-S8 & 35 & 51.9 & 9.4 & 5.5 \\
B-6B-S8 & 34 & 35.4 & 11.2 & 3.2 \\
B-CNB-S8 & 30 & 14.8 & 4.5 & 3.3 \\
\hline
\end{tabular}

${ }^{\text {a }}$ Estimated by GPC using standard polystyrene.

yield in the polymerization. The results of the polymerization are shown in Table II.

The weight average molecular weights of polymers estimated by GPC using polystyrene standards ranged from 6.5 to $51.9 \times 10^{4}\left(M_{w} / M_{n}=1.5-5.5\right)$. Although the molecular weight distribution of the polymers having cyanobiphenyl as the mesogen was considerably narrow as a polymer formed by radical polymerization, ${ }^{16,17}$ that of the polymers obtained in bulk in this study was rather wide. Solution polymerization in benzene gave polymers of much sharper molecular weight distribution (an example PB-1B-S6: $M_{w}=9.6 \times 10^{3} ; M_{w} / M_{n}=1.9$ ). Some cross-linking may have occurred under bulk conditions.

\section{Polymer Structure by ${ }^{1} H N M R$ and ${ }^{13} C N M R$}

There are four structural isomers, namely, cis-1,4-, trans-1,4-, 1,2-, 3,4-structures in the polydiene mainchain having a substituent at 2-position. In the case of polydiene with siloxane linkage in the spacer, cis-1,4and trans-1,4-structures correspond to E-1,4- and Z-1,4structures, respectively. ${ }^{16,17}$

The ratio of structural units very much depends on the method of polymerization. ${ }^{19-21}$ For instance, polyisoprene rich in trans-1,4-structure is obtained by the radical polymerization, while anionic polymerization by organolithium reagent or coordination polymerization by transition metal catalyst gives $c i s-1,4$-structure. Since the structure of main chain affects the characteristics of polymer, the control of structure is one of the most important factors.

The ${ }^{1} \mathrm{H}$ NMR spectra and DEPT spectra of polymers indicate that the polymers are formed by 1,4-opening of the diene function. NOESY spectra support that the olefinic proton and trimethylsilyl groups are situated in a cis relation with respect to the carbon-carbon double bond. Thus it was elstablished that the polymer main chain takes one predominant stereochemistry, namely, E-1,4-. ${ }^{16,17}$ This stereochemistry was also suggested by Nakahama. ${ }^{22-25}$
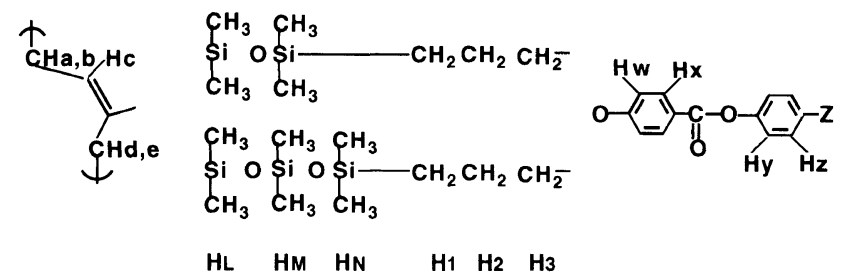
Table III. Thermal behavior of intermediate A- $n$ B and A-CNB

\begin{tabular}{|c|c|c|c|c|c|}
\hline \multirow{3}{*}{ Compound } & \multicolumn{4}{|c|}{$\mathrm{DSC} /{ }^{\circ} \mathrm{C}^{\mathrm{a}}$} & \multirow{3}{*}{ Texture } \\
\hline & \multicolumn{2}{|c|}{ Cooling } & \multicolumn{2}{|c|}{ 2nd Heating } & \\
\hline & $T_{\mathrm{IM}}$ & $T_{\mathrm{MK}}$ & $T_{\mathrm{KM}}$ & $T_{\mathrm{MI}}$ & \\
\hline A-1B & 73.1 & 65.5 & - & 86.2 & Schlieren $^{\mathrm{b}}$ \\
\hline A-3B & 75.5 & 55.8 & 69.3 & 75.4 & Schlieren $^{\mathrm{c}}$ \\
\hline A-4B & 88.0 & 46.0 & 67.4 & 87.2 & Schlieren $^{\mathrm{c}}$ \\
\hline A-5B & 78.6 & 26.5 & 62.8 & 78.0 & Schlieren $^{\circ}$ \\
\hline A-6B & 82.6 & 25.6 & 56.8 & 81.3 & Schlieren $^{\mathrm{c}}$ \\
\hline $\mathrm{A}-\mathrm{CNB}$ & 89.2 & 69.9 & - & 99.8 & n.d. ${ }^{\mathrm{d}}$ \\
\hline
\end{tabular}

${ }^{a}$ Determined at the starting point of transition. Cooling cycle. ${ }^{\mathrm{c}}$ Cooling and heating cycle. ${ }^{\mathrm{d}}$ n.d., phase could not be determined.

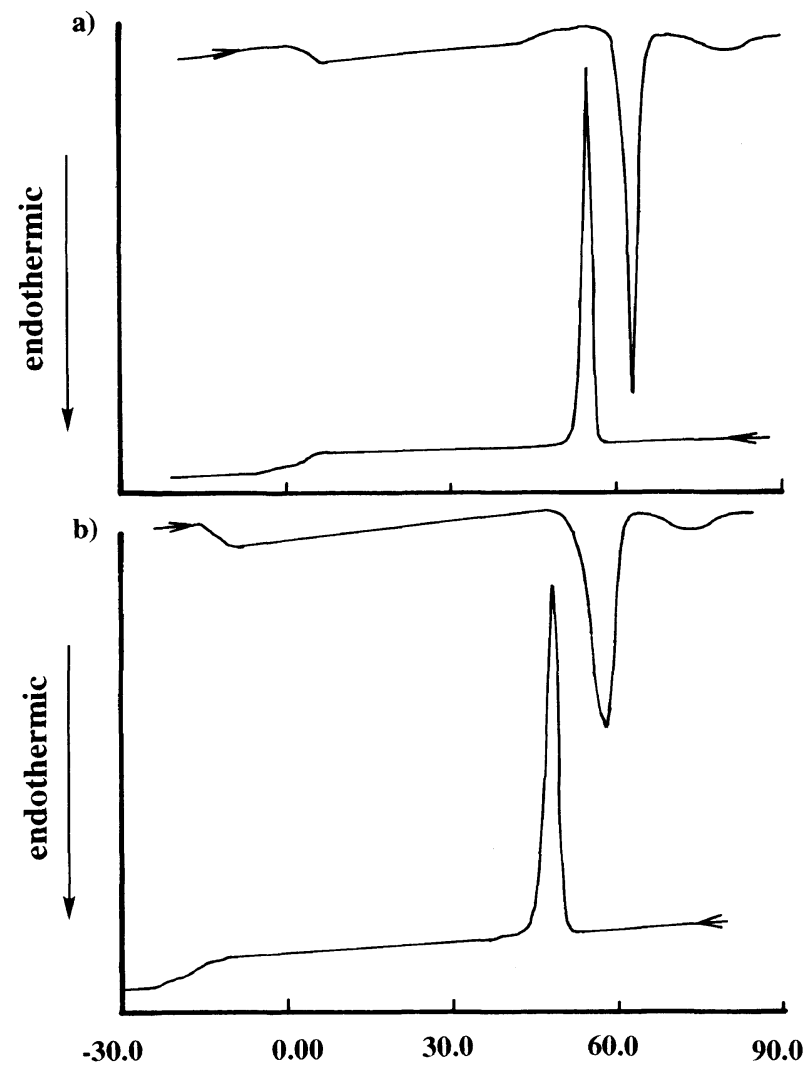

Temperature $\left({ }^{\circ} \mathrm{C}\right)$

Figure 1. DSC curves of a) PB-4B-S6 and b) PB-4B-S8 in second heating $\rightarrow$ and cooling $\longrightarrow$ cycles.

\section{Thermal Behavior of Monomers and Polymers}

Intermediate 4-alkyloxyphenyl 4-allyloxybenzoate (A$n \mathrm{~B}) \mathrm{s}$ or 4-cyanophenyl 4-allyloxybenzoate (A-CNB) showed two transition temperatures in heating and cooling cycles (Table III). The transition temperatures showed odd even effect depending upon the number of carbon atoms in the tail group. Although some monomers including B-4B-S6, B-CNB-S6, and B-CNB-S8 showed two or three thermal transitions in DSC analysis, liquid crystalline phase could not be seen for any monomer studied.

The DSC analysis of PB-4B-S6 and PB-4B-S8 is shown in Figure 1.

The polymers showed glass transition temperature and primary transition in both heating and cooling cycles.
Table IV. Thermal behavior of polymers

\begin{tabular}{|c|c|c|c|c|c|}
\hline \multirow{3}{*}{ Polymer } & \multicolumn{4}{|c|}{$\mathrm{DSC} /{ }^{\circ} \mathrm{C}^{\mathrm{a}}$} & \multirow{3}{*}{ Texture } \\
\hline & \multicolumn{2}{|c|}{ Cooling } & \multicolumn{2}{|c|}{ 2nd Heating } & \\
\hline & $T_{\mathrm{g}}$ & $T_{\mathrm{IM}}$ & $T_{\mathrm{g}}$ & $T_{\mathrm{MI}}$ & \\
\hline PB-1B-S6 & -6 & 4.5 & -10.9 & $46.2(71)$ & Fan like marvel \\
\hline PB-3B-S6 & 4 & 28.8 & -4.0 & $29.8(55)$ & Fan like \\
\hline PB-4B-S6 & 6 & 56.9 & 1.9 & $59.8(74)$ & Fan like \\
\hline PB-5B-S6 & 0 & 36.0 & -14.1 & $30.0(57)$ & Fan like \\
\hline PB-6B-S6 & 0 & $42.6^{b}$ & -13.9 & $35.5^{\mathrm{c}}(60)$ & Fan like \\
\hline PB-CNB-S6 & 10 & 76.3 & -1.2 & $84.1(-)^{d}$ & Fan \\
\hline PB-1B-S8 & - & 26.6 & -13.3 & $45.2(59)$ & Schlieren like \\
\hline PB-4B-S8 & -12 & 51.3 & -15.3 & $54.2(70)$ & Fan \\
\hline PB-6B-S8 & -3 & 54.0 & -17.5 & $57.6(74)$ & Fan \\
\hline PB-CNB-S8 & -10 & 26.8 & -16.2 & $25.2(69)$ & Fan \\
\hline
\end{tabular}

${ }^{a}$ Determined at the starting point of transition. ${ }^{\mathrm{b}}$ Second and third peaks at 54 and $49^{\circ} \mathrm{C}$. ${ }^{c}$ Third peak at $54^{\circ} \mathrm{C}$. ${ }^{d}$ Exothermic peaks at 50 and $55^{\circ} \mathrm{C}$.

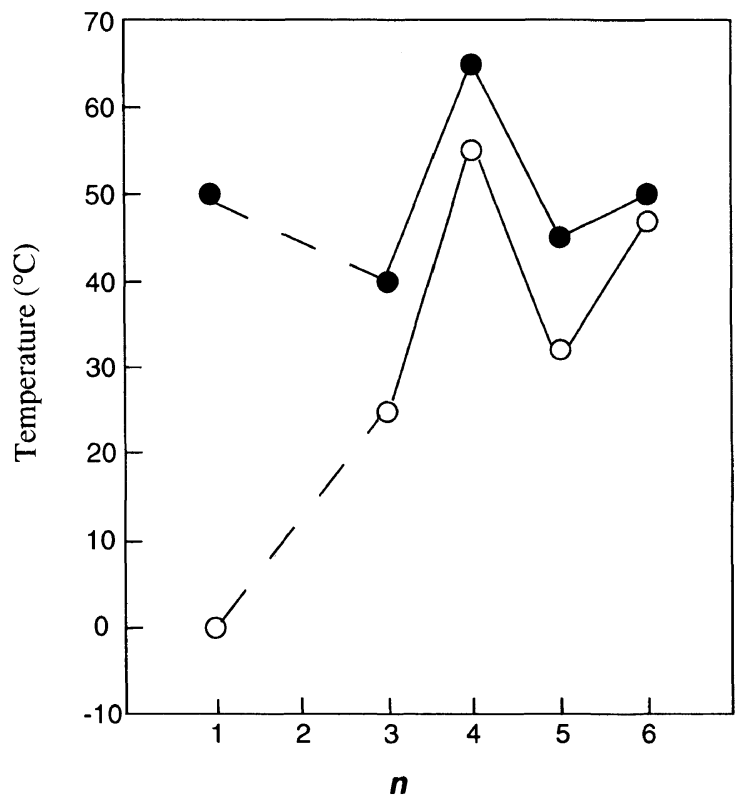

Figure 2. Effects of the length of the tail group on transition temperatures. - heating $\left(T_{\mathrm{MI}}\right) ; \bigcirc$, cooling $\left(T_{\mathrm{IM}}\right) ; n=$ number of carbon atoms in the tail group.

The transition enthalpies of primary transitions are around $20-30 \mathrm{~mJ} \mathrm{mg}^{-1}$. Second primary transition of smaller enthalpy was observed at higher temperature in heating cycle. PB-1B-S6 showed an exothermic transition in heating cycle at $7^{\circ} \mathrm{C}$ in addition to the above transition. The transition temperatures of the polymers are summarized in Table IV. Generally, polymers with S8 spacer showed lower transition temperatures. The second transition is shown in parentheses. Detailed study is needed to clarify this phenomenon. The effects of the length of the tail groups are shown in Figure 2. Odd even effect of the spacer length on the transition temperature was observed. The hydrogenated polymers showed sharp transition around $-40^{\circ} \mathrm{C}$ in heating cycle. This transition seems related to change in the conformation of the spacer.

Phase Structure under Optical Polarization Micrograph Intermediate A- $n$ B's take the nematic phase (Table 
a)

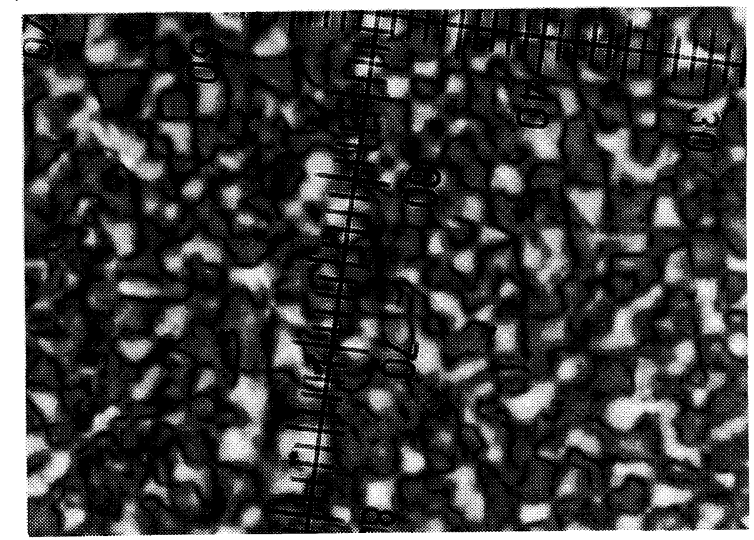

b)

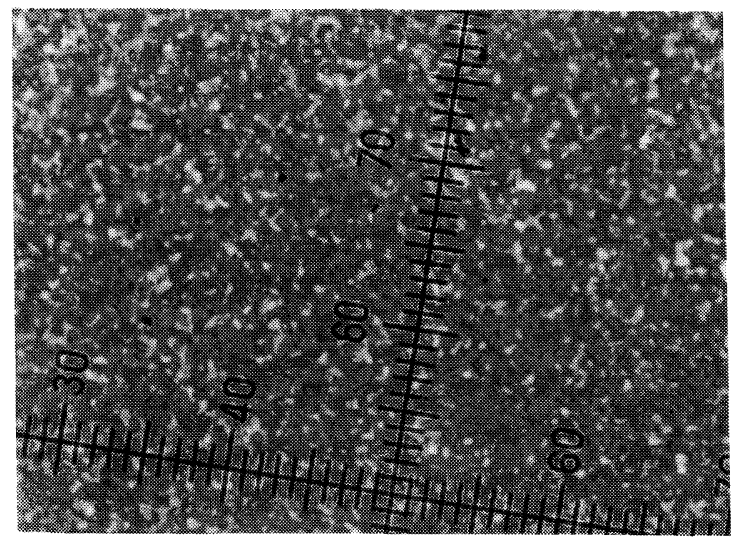

c)

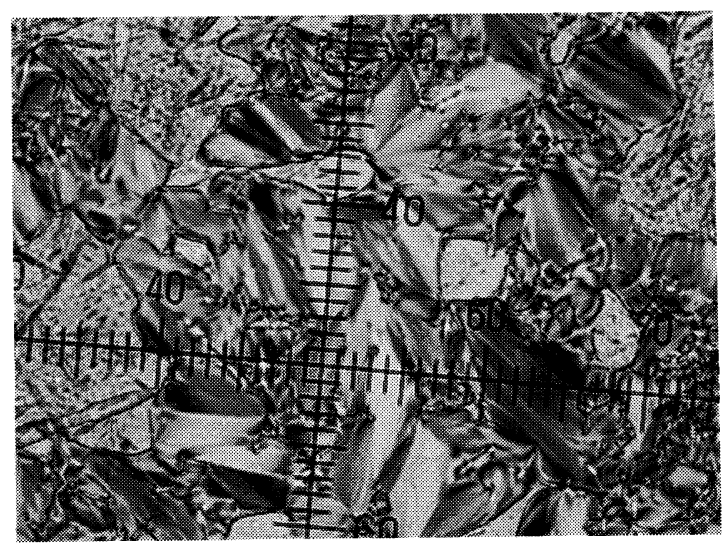

d)

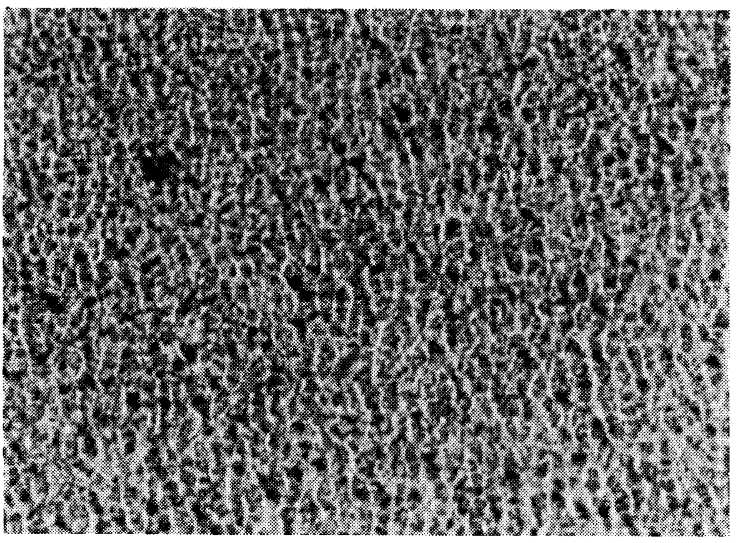

e)

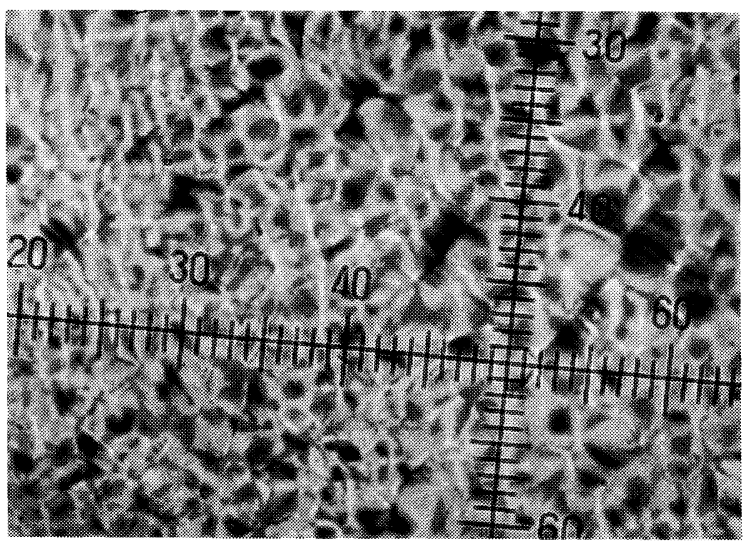

f)

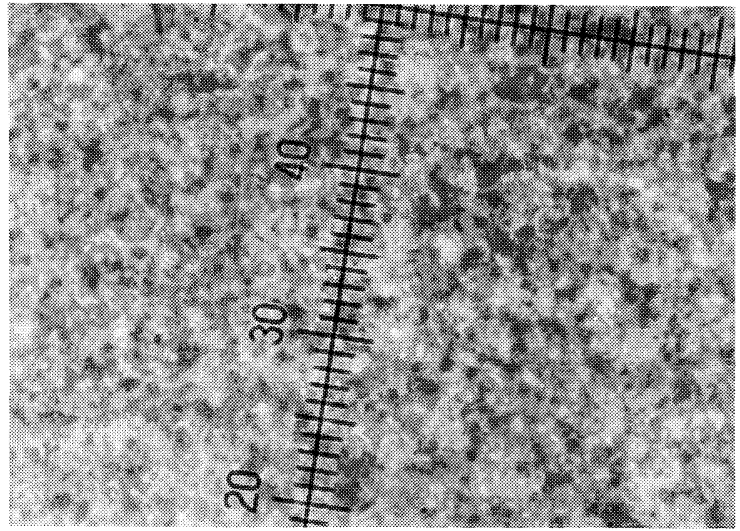

\section{$100 \mu \mathrm{m}$}

Figure 3. Optical polarization micrographs of a) PB-1B-S6 at $45^{\circ} \mathrm{C}$, b) PB-4B-S6 at $56^{\circ} \mathrm{C}$, c) $\mathrm{PB}-\mathrm{CNB}-\mathrm{S} 6$ at $\left.80^{\circ} \mathrm{C}, \mathrm{d}\right) \mathrm{PB}-1 \mathrm{~B}-\mathrm{S} 8$ at $48^{\circ} \mathrm{C}$, e) $\mathrm{PB}-$ $4 \mathrm{~B}-\mathrm{S} 8$ at $54^{\circ} \mathrm{C}$, and $\mathrm{f}$ ) PB-CNB-S8 at r.t.

III). No monomer was concluded to take a liquid crystalline state.

Polymers except for PB-CNB-S6, PB-4B-S8, PB-6BS8, and PB-CNB-S8 showed texture difficult to assign. $\mathrm{X}$-Ray diffraction analysis of the polymers revealed the existence of sharp diffraction at $2 \theta=7.0^{\circ}$, which strongly suggests that all the polymers take the smectic phase except PB-1B-S6 and PB-1B-S8 which take the nematic phase. As can be seen that intermediate A- $n \mathrm{~B}$ 's take the nematic phase, the benzoate mesogens usually give rise to the nematic phase in ordinary side-chain liquid crystalline polymers like polymers having polysiloxane, polymethacrylate as main chain. A combination of both flexible polydiene main chain and siloxane spacer apparently made it easy for the mesogens to be organized in the smectic phase. This was more clearly seen for polymers with S8 spacer than those with S6 spacer group. Typical optical polarization micrographs are shown in 
Figure 3. Although all hydrogenated polymers showed transition higher than glass transition temperature, no liquid crystalline state was identified for any polymer.

\section{CONCLUSION}

Polydiene was found to act as a suitable main chain component for a side-chain liquid crystalline polymer with various benzoate derivatives as the mesogenic groups. The introduction of siloxane linkage into the spacer group is effective to give a better organized smectic A mesophase of lower transition temperature. The importance of the flexibility of the main chain and spacer is stressed.

Acknowledgments. Financial supports from a Grantin-Aid for Scientific Research (07651078, 07555595, 07246219) from the Ministry of Education, Science, Sports, and Culture are gratefully acknowledged.

\section{REFERENCES}

1. H. Finkelmann, H. Ringsdorf, and J. H. Wendorff, Makromol. Chem., 179, 273 (1978).

2. H. Finkelmann, M. Happ, M. Portugal, and H. Ringsdorf, Makromol. Chem., 179, 1978 (1978).

3. V. P. Shibaev, S. G. Konstromin, N. A. Plate, S. A. Ivanov, V. Ju. Vetrov, and I. A. Yakovlev, Polym. Commun., 24, 364 (1983).

4. N. A. Plate and V. P. Shibaev, Ed., "Comb-Shaped Polymers and Liquid Crystals," Plenum Press, New York, N.Y., 1987.

5. C. B. McArdle, Ed., "Side Chain Liquid Crystal Polymers," Chapman and Hall, New York, N.Y., 1989.
6. A. A. Collyer, Ed., "Liquid Crystal Polymers: From Structures to Applications," Elsevire, Barking, 1992.

7. P. L. Magagnini, F. Andruzzi, and G. F. Benetti, Macromolecules, 13, $12(1980)$.

8. B. Durairaj, E. T. Samulski, and T. M. Shaw, Macromolecules, 23, $1229(1990$,

9. J. J. Mallon and S. W. Kantor, Macromolecules, 22, 2070 (1989).

10. J. J. Mallon and S. W. Kantor, Macromolecules, 23, 1249 (1990).

11. C. T. Imrie, F. E. Karasz, and G. S. Attard, Macromolecules, 25, 1278 (1992).

12. C. T. Imrie, F. E. Karasz, and G. S. Attard, Macromolecules, 27, 1578 (1994).

13. V. Percec, Makromol. Chem., Macromol. Symp., 13/14, 397 (1988).

14. M. Engel, B. Hisgen, R. Keller, W. Kreuder, B. Reck, H. Ringsdorf, H.-W. Schmidt, and P. Tschirner, Pure \& Appl. Chem. 57, 1009 (1985).

15. Y. Nagase and Y. Takamura, Makromol. Chem., 193, 1225 (1992).

16. Y. Kawakami, K. Toida, and Y. Ito, Macromolecules, 26, 1177 (1993).

17. Y. Kawakami and K. Toida, Macromolecules, 28, 1177 (1995).

18. S. Nunomoto and Y. Yamashita, J. Org. Chem., 44, 4788 (1979).

19. G. Allen, J. C. Bevington, G. C. Eastmond, A. Ledwith, S. Russo, and P. Sigwalt, Ed., "Comprehensive Polymer Science," Vol. 4, Pergamon, Oxford, 1989.

20. F. A. Bovey, "Chain Structure and Conformation of Macromolecules," Academic Press, New York, N.Y., 1982.

21. D. B. Patterson and A. F. Halasa, Macromolecules, 24, 1583 (1991).

22. K. Takenaka, T. Hattori, A. Hirao, and S. Nakahama, Macromolecules, 22, 1563 (1989).

23. K. Takenaka, K. Kato, T. Hattori, A. Hirao, and S. Nakahama, Macromolecules, 23, 3619 (1990).

24. K. Takenaka, T. Hattori, A. Hirao, and S. Nakahama, Macromolecules, 25, 96 (1992).

25. K. Takenaka, A. Hirao, and S. Nakahama, Makromol. Chem. 193, 1943 (1992). 